Research Article

\title{
Quantitative Characteristics of Toxic Compounds According to the Solvent Type
}

\author{
Young-Ji An $\mathbb{D}^{1},{ }^{1}$ Seong-Jin Choi $\mathbb{D}^{2},{ }^{2}$ Yong-Hyun Kim $\mathbb{D}^{2,3}$ and Kyuhong Lee $\mathbb{D}^{3,4}$ \\ ${ }^{1}$ Department of Toxicology Evaluation, Konyang University, Daejeon, Republic of Korea \\ ${ }^{2}$ Jeonbuk Department of Inhalation Research, Korea Institute of Toxicology, Jeongeup 56212, Republic of Korea \\ ${ }^{3}$ Human and Environmental Toxicology, University of Science and Technology, Daejeon 34113, Republic of Korea \\ ${ }^{4}$ National Center for Efficacy Evaluation of Respiratory Disease Product, Korea Institute of Toxicology, \\ Jeongeup 56212, Republic of Korea
}

Correspondence should be addressed to Yong-Hyun Kim; yonghyun.kim@kitox.re.kr and Kyuhong Lee; khlee@kitox.re.kr

Received 30 September 2018; Accepted 24 March 2019; Published 30 April 2019

Academic Editor: Paolo Montuori

Copyright (C) 2019 Young-Ji An et al. This is an open access article distributed under the Creative Commons Attribution License, which permits unrestricted use, distribution, and reproduction in any medium, provided the original work is properly cited.

The quantitative analysis of target substances is an important part of assessing the toxicity of diverse materials. Usually, the quantitation of target compounds is conducted by instrumental analysis such as chromatography and capillary electrophoresis. If solvents are used in the pretreatment step of the target analyte quantification, it would be crucial to examine the solvent effect on the quantitative analysis. Therefore, in this study, we assessed the solvent effects using four different solvents (methanol, hexane, phosphate buffered saline (PBS), and dimethyl sulfoxide (DMSO)) and three toxic compounds (benzene, toluene, and methylisothiazolinone (MIT)). Liquid working standards containing the toxic compounds were prepared by dilution with each solvent and analyzed by gas chromatography-mass spectrometry (GC-MS). As a result, we found that the response factor (RF) values of the target analytes were different, depending on the solvent types. In particular, benzene and toluene exhibited their highest RF values $\left(33,674 \mathrm{ng}^{-1}\right.$ and $78,604 \mathrm{ng}^{-1}$, respectively) in hexane, while the RF value of MIT was the highest $\left(9,067 \mathrm{ng}^{-1}\right)$ in PBS. Considering the correlation $\left(R^{2}\right)$ and relative standard deviation (RSD) values, all target analytes showed fairly good values $\left(R^{2}>0.99\right.$ and $\left.\mathrm{RSD}<10 \%\right)$ in methanol and DMSO. In contrast, low $R^{2}(0.0562)$ and high RSD (10.6\%) values of MIT were detected in hexane, while benzene and toluene exhibited relatively low $R^{2}$ and high RSD values in PBS (mean $R^{2}=0.9892 \pm 0.0146$ and mean $\mathrm{RSD}=13.3 \pm 4.1 \%$ ). Based on these findings, we concluded that the results and reliability of the quantitative analysis change depending on the analyte and solvent types. Therefore, in order to accurately assess the toxicity of target compounds, reliable analytical data should be obtained, preferentially by considering the solvent types.

\section{Introduction}

Chemical products that are generally used to clean, sanitize, and disinfect are widely employed in our living environments. However, several of these are known to contain toxic compounds, which can damage the human health and natural environment $[1,2]$. Due to their hazardous properties, these chemicals are usually regulated through a toxicology analysis such as safety assessment and toxicity testing [3]. In the toxicity testing, the accurate exposure of target chemicals to experimental animals or cells is important. As such, the stability of target chemicals should first be evaluated and ensured, the latter of which is commonly performed with the use of solvents $[4,5]$. In case of the U.S. Environmental Protection Agency, the use of acetone, dimethylformamide (DMF), dimethyl sulfoxide (DMSO), and methanol as solvents is recommended for toxicity tests on aquatic invertebrates [6].

In general, a variety of solvents have been used to performing toxicity test $[7,8]$. For example, in the case of an inhalation toxicity testing, solvents are mainly used for the sample extraction, absorption, and dilution steps. More specifically, if the filter sampling is conducted, the inhalable samples are first collected by filters (i.e., glass, quartz, or Teflon filters), after which the samples loaded on the filters are extracted and diluted by solvents [9-12]. Solvents are 
also used as the absorption solution to collect directly the inhalable samples [13]. In contrast, in the case of a cytotoxicity test, solvents are used for the storage and extraction of target analytes from cells $[14,15]$. For this purpose, phosphate buffered saline (PBS) has been recommended as a suitable buffer solution to maintain the appropriate $\mathrm{pH}$ for cell storage $[16,17]$. In addition, DMSO can be used as a sample extractant and cryoprotectant of cultured cells in biochemistry and cell biology [18].

Reportedly, the calibration results of target compounds can differ depending on the solvent effect due to the use of liquid samples [19, 20]. For example, Campos et al. [21] examined the reaction of an imidazole derivative with organic solvents by analyzing the imidazole samples derivatized from diethyl 2,4-dinitrophenyl phosphate and DMSO or distilled water as a solvent. As a result, they found that the imidazole derivative reaction increases in DMSO and decreases in distilled water, which indicates that the reactivity of derivation is different depending on the solvent type and that the reliability results can affect the quantitative analysis.

In this study, we investigated the solvent effect of toxic compounds in relation to their calibration characteristics. Methanol $(\mathrm{MeOH})$, hexane, PBS, and DMSO, which are commonly used in the chemical and biological analysis, were selected as target solvents, while benzene, toluene, and methylisothiazolinone (MIT) were selected as target analytes (Table 1). From these, benzene and toluene are generally identified as carcinogenic, as they have the potential to damage the generative functions in humans upon transmission [22], whereas MIT is commonly known as the main component in humidifier disinfectants. The standard solutions containing the target analytes and solvents were analyzed using a gas chromatography (GC) equipped with a mass spectrometry (MS), which provided the calibration data to assess the solvent effects.

\section{Materials and Methods}

2.1. Preparation of the Working Standards (WSs). A total of three target compounds (benzene, toluene, and MIT) and four solvents $(\mathrm{MeOH}$, hexane, PBS, and DMSO) were selected to investigate the solvent effect. WSs of these three target compounds were prepared in the same way using each solvent. Reagent grade chemicals (RGCs) were purchased at $\geq 95 \%$ purity: (1) $99.5 \%$ (benzene and toluene), (2) $95 \%$ (MIT), and (3) 99.9\% (MeOH, hexane, and DMSO) (SigmaAldrich, USA). PBS (1x, pH 7.4, Gibco BRL) was purchased from Life Technologies (Frederick, MD, USA). Primary standards (PSs) were prepared (PS-1 and PS-2) by mixing the RGCs with benzene and toluene or with MIT, respectively, with concentrations of $8,736 \mathrm{ng} \cdot \mu \mathrm{L}^{-1}$ (benzene), $8,627 \mathrm{ng} \cdot \mu \mathrm{L}^{-1}$ (toluene), and 90,000 ng. $\mu \mathrm{L}^{-1}$ (MIT). The first working standards (1st-WSs) were prepared by mixing $100 \mu \mathrm{L}$ of PS- 1 and PS- 2 each and $1800 \mu \mathrm{L}$ of the respective solvent in a $2 \mathrm{~mL}$ vial, resulting in final concentrations (ng. $\mu \mathrm{L}^{-1}$ ) of 416 (benzene), 411 (toluene), and 4,286 (MIT). Four different solvents were used to form the 1st-WSs: $\mathrm{MeOH}$ (1st-WS-M), hexane (1st-WS-H), PBS (1st-WS-P), and DMSO (1st-WS-D). The final working standards (F-WSM, F-WS-H, F-WS-P, and F-WS-D) for the five-point calibrations were prepared by diluting each 1st-WS with the respective solvent to prepare five different concentrations: (1) benzene: $8.32,20.8,41.6,83.2$, and $208 \mathrm{ng} \cdot \mu \mathrm{L}^{-1}$, (2) toluene: $8.22,20.5,41.1,82.2$, and $205 \mathrm{ng} \cdot \mu \mathrm{L}^{-1}$, and (3) MIT: $85.7,214,429,857$, and $2,143 \mathrm{ng} \cdot \mu \mathrm{L}^{-1}$ (Figure $1(\mathrm{a})$ ). Detailed information on the preparation of the WSs is shown in Table 2.

2.2. Instrumental System. A GC (GC-2010, Shimadzu, Japan) equipped with an MS (GCMS-QP2010 ultra, Shimadzu, Japan) was employed to quantify the toxic compounds in the solvents (Figure 1(b)). Since the F-WSs contained different solvents, the calibration characteristics of the toxic compounds according to the solvent effects were assessed.

In the analysis, $1 \mu \mathrm{L}$ samples from the F-WSs were injected into the $\mathrm{GC}$ injector (at $250^{\circ} \mathrm{C}$ ) using the autosampler (AOC-5000, Shimadzu, Japan). The target analytes were then transferred to the Rtx-5MS column (diameter: $0.25 \mathrm{~mm}$, length: $60 \mathrm{~m}$, and thickness: $0.25 \mu \mathrm{m}$, Restek Corporation, USA) for separation using a carrier gas ( $\mathrm{He}>99.999 \%$, flow rate of $2.41 \mathrm{~mL} \cdot \mathrm{min}^{-1}$ (constant flow)). The oven temperature of the GC was initially set to $40^{\circ} \mathrm{C}$ for $4 \mathrm{~min}$, after which it was ramped at $15^{\circ} \mathrm{C} \cdot \mathrm{min}^{-1}$ to $145^{\circ} \mathrm{C}$, and finally ramped at $70^{\circ} \mathrm{C} \cdot \mathrm{min}^{-1}$ to $285^{\circ} \mathrm{C}$, thereby giving a total run time of $13 \mathrm{~min}$.

The target analytes separated by the GC system were then detected by the MS system. Both the interface and ion source temperatures were set to $250^{\circ} \mathrm{C}$. The target analytes were quantified in a total ion chromatogram (TIC) mode in a mass range of $30-500 \mathrm{~m} / \mathrm{z}$. Extracted ion chromatographic (EIC) mode was subsequently applied to the minimized interfaces using significant ions identified from the spectrum of each target analyte (Table 1). Detailed setting information of the analysis instrument is presented in Table 3.

\section{Result and Discussion}

3.1. Calibration Characteristics of the Toxic Compounds According to the Solvent Type. The calibration results of the target analytes obtained by GC-MS analysis were provided in terms of the response factor (RF, $\mathrm{ng}^{-1}$ ), coefficient of determination $\left(R^{2}\right)$, relative standard error (RSD, \%), and limit of detection (LOD, ng) (Table 4).

Notably, the RF value of each target analyte was different, depending on the solvent type. The obtained RF values were normalized against the highest $\mathrm{RF}$ value in the following way: normalized-RF $(\mathrm{N}-\mathrm{RF})=\mathrm{RF} / \mathrm{RF}(\max )$ (Table 4). Benzene and toluene had relatively high $\mathrm{N}-\mathrm{RF}$ values (above 0.77) in hexane and DMSO, while in PBS (highly polar solvent), their N-RF values were significantly lower (0.34 and 0.27 , respectively). In contrast, MIT exhibited the highest $\mathrm{N}$-RF value in PBS $(\mathrm{N}-\mathrm{RF}=1)$, whereas in hexane, the N-RF value of MIT was low $(\mathrm{N}-\mathrm{RF}=0.12)$.

The calibration results derived in terms of $R^{2}$ and RSD (\%) were similar to the patterns observed in the RF values (Figure 2). In particular, the $R^{2}$ values of benzene, toluene, 
TABLE 1: Basic information on target compounds and solvents.

\begin{tabular}{|c|c|c|c|c|c|c|c|c|}
\hline $\begin{array}{l}\text { Chemical } \\
\text { group }\end{array}$ & $\begin{array}{c}\text { Full } \\
\text { name }\end{array}$ & $\begin{array}{l}\text { Short } \\
\text { name }\end{array}$ & $\begin{array}{l}\text { Molecular } \\
\text { formula }\end{array}$ & $\begin{array}{l}\text { Molecular weight } \\
\left(\mathrm{g} \cdot \mathrm{mol}^{-1}\right)\end{array}$ & $\begin{array}{c}\text { Density } \\
\left(\mathrm{g} \cdot \mathrm{mL}^{-1}\right)\end{array}$ & $\mathrm{m} / \mathrm{z}^{\mathrm{a}}$ & $\begin{array}{c}\text { CAS } \\
\text { number }\end{array}$ & $\begin{array}{l}\text { Chemical } \\
\text { structure }\end{array}$ \\
\hline \multirow{3}{*}{$\begin{array}{l}\text { Target } \\
\text { compound }\end{array}$} & Benzene & - & $\mathrm{C}_{6} \mathrm{H}_{6}$ & 78.11 & 0.874 & 78 & $71-43-2$ & \\
\hline & Toluene & - & $\mathrm{C}_{6} \mathrm{H}_{5} \mathrm{CH}_{3}$ & 92.141 & 0.867 & 91 & $50643-04-4$ & \\
\hline & Methylisothiazolinone & MIT & $\mathrm{C}_{4} \mathrm{H}_{5} \mathrm{NOS}$ & 115.1 & 1.35 & 115 & $2682-20-4$ & \\
\hline \multirow{4}{*}{$\begin{array}{l}\text { Solvent } \\
\text { compound }\end{array}$} & Methanol & $\mathrm{MeOH}$ & $\mathrm{CH}_{3} \mathrm{OH}$ & 32.04 & 0.792 & 31 & $67-56-1$ & \\
\hline & Hexane & - & $\mathrm{C}_{6} \mathrm{H}_{14}$ & 86.18 & 0.6606 & 57 & $110-54-3$ & \\
\hline & Phosphate buffered saline & PBS & $\mathrm{Cl}_{2} \mathrm{H}_{3} \mathrm{~K}_{2} \mathrm{Na}_{3} \mathrm{O}_{8} \mathrm{P}_{2}$ & 411.029 & 0.0648 & NA & NA & \\
\hline & Dimethyl sulfoxide & DMSO & $\mathrm{C}_{2} \mathrm{H}_{6} \mathrm{OS}$ & 78.13 & 1.1004 & $45,63,78$ & $67-68-5$ & \\
\hline
\end{tabular}

${ }^{\mathrm{a}}$ Main spectra of the target compounds. NA, not available.
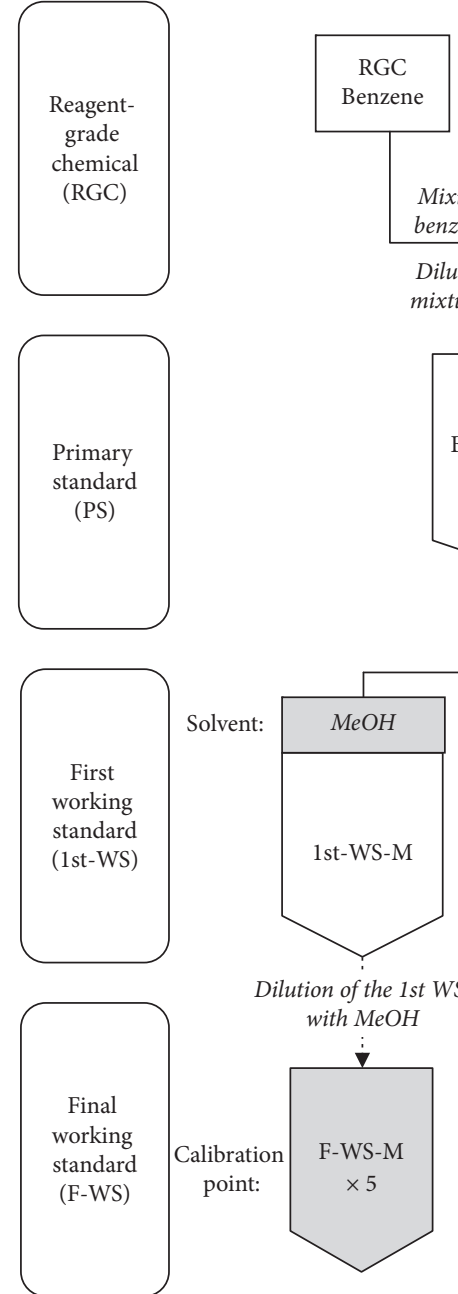
Solvent:

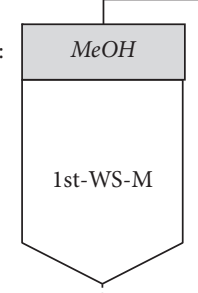

benzene and toluene

Dilution of the RGC mixture using $\mathrm{MeOH}$ solvent

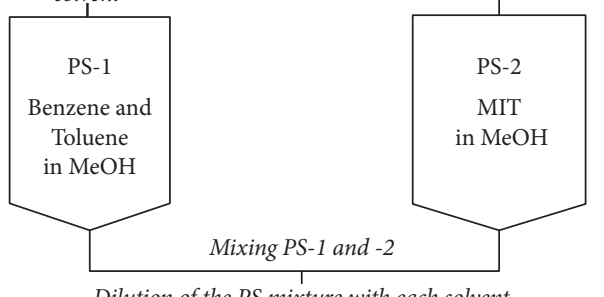

Dilution of the PS mixture with each solvent

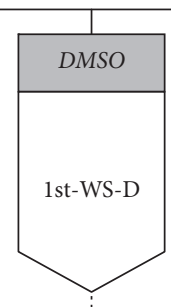

Dilution of the 1st WS with DMSO
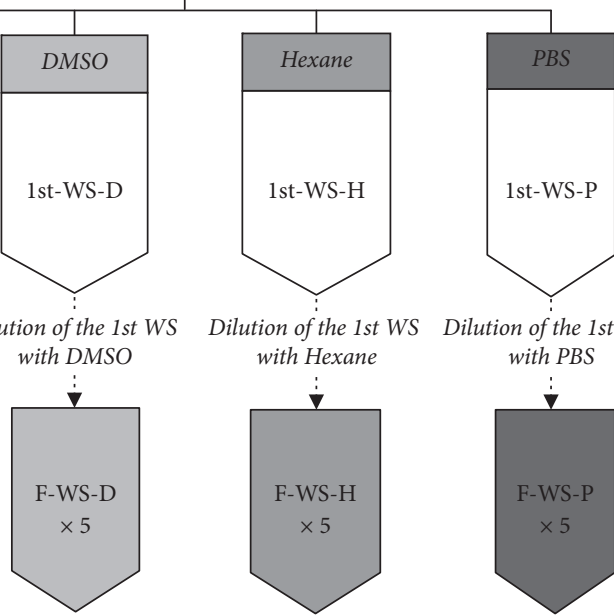

Dilution of the 1st WS Dilution of the 1st WS

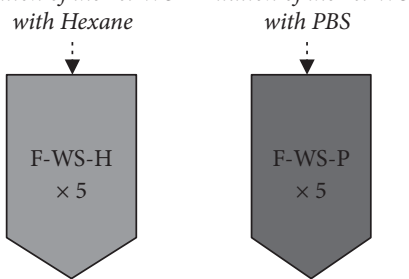

(a)

Figure 1: Continued. 

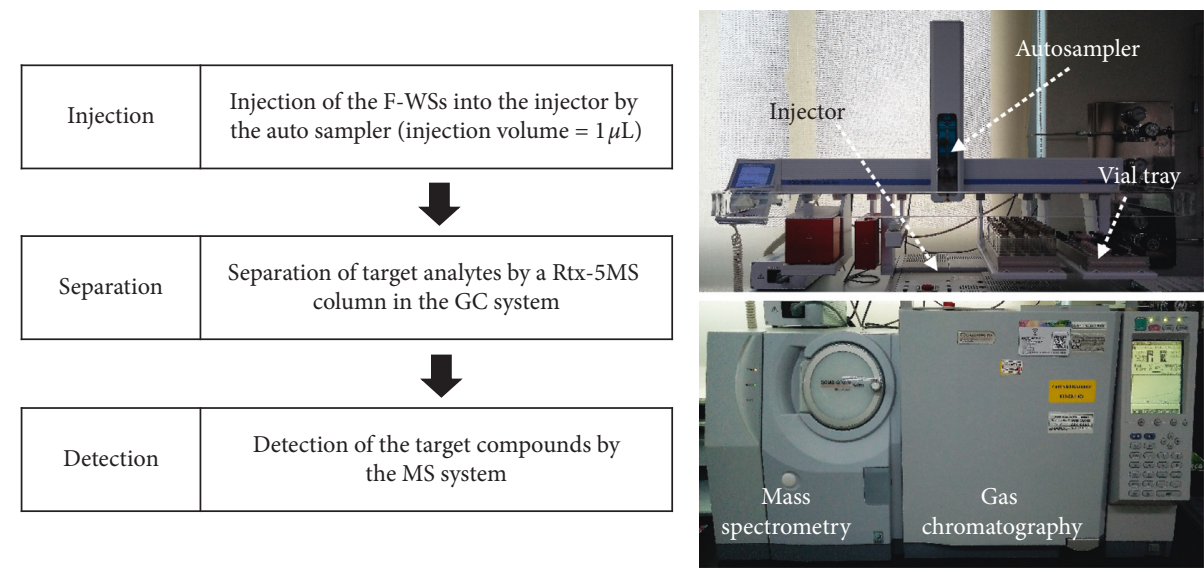

(b)

FIGURE 1: A plot of the experimental sequence for the preparation and analysis of the working standards (WSs). (a) Preparation of working standards. (b) Analysis of the working standards.

TABLE 2: Preparation of working standards (WSs) containing three target compounds (benzene, toluene, and MIT) based on four different solvents (MeOH, DMSO, hexane, and PBS).

\begin{tabular}{|c|c|c|c|c|c|c|}
\hline \multicolumn{7}{|c|}{ (a) Reagent grade chemical (RGC) } \\
\hline Compound name & Benzene & Toluene & MIT & & & \\
\hline Concentration (\%) & 99.5 & 99.5 & 95 & & & \\
\hline Density $\left(\mathrm{g} \cdot \mathrm{mL}^{-1}\right)$ & 0.878 & 0.867 & 1.35 & & & \\
\hline \multicolumn{7}{|c|}{ (b-1) The first primary standard (PS-1) } \\
\hline Compound & Benzene & Toluene & $\mathrm{MeOH}$ & & & \\
\hline Volume $(\mu \mathrm{L})$ & 20 & 20 & 1,960 & & & \\
\hline Dilution fraction & 0.010 & 0.010 & & & & \\
\hline Concentration (ng. $\mu \mathrm{L}^{-1}$ ) & 8,736 & 8,627 & & & & \\
\hline \multicolumn{7}{|c|}{ (b-2) The second primary standard (PS-2) } \\
\hline Compound & MIT & & & & & \\
\hline Mass (mg) & 180 & & & & & \\
\hline Volume $(\mathrm{mL})$ & 2.000 & & & & & \\
\hline Concentration $\left(\mathrm{ng} \cdot \mu \mathrm{L}^{-1}\right)$ & 90,000 & & & & & \\
\hline \multicolumn{7}{|c|}{ (c) The first working standard (WS) } \\
\hline Working standard & \multicolumn{2}{|c|}{ PS-1 } & PS-2 & \multicolumn{3}{|l|}{ Solvent $\mathrm{t}^{\mathrm{a}}$} \\
\hline Compound & Benzene & Toluene & MIT & \multirow{4}{*}{1,800} & & \\
\hline Volume $(\mu \mathrm{L})$ & & & 100 & & & \\
\hline Dilution fraction & & & 0.05 & & & \\
\hline Concentration $\left(\mathrm{ng} \cdot \mu \mathrm{L}^{-1}\right.$ ) & 416 & 411 & 4,286 & & & \\
\hline \multicolumn{7}{|c|}{ (d) The final working standard at 5 concentration levels } \\
\hline \multirow{2}{*}{ Order } & \multicolumn{2}{|c|}{ Mixing volume $(\mu \mathrm{L})$} & \multirow{2}{*}{ Dilution fraction } & \multicolumn{3}{|c|}{ Concentration $\left(\mathrm{ng} \cdot \mu \mathrm{L}^{-1}\right)$} \\
\hline & 1st L-WS & Solvent & & Benzene & Toluene & MIT \\
\hline 1 & 40 & 1,960 & 0.020 & 8.32 & 8.22 & 85.7 \\
\hline 2 & 100 & 1,900 & 0.050 & 20.8 & 20.5 & 214 \\
\hline 3 & 200 & 1,800 & 0.100 & 41.6 & 41.1 & 429 \\
\hline 4 & 400 & 1,600 & 0.20 & 83.2 & 82.2 & 857 \\
\hline 5 & 1,000 & 1,000 & 0.50 & 208 & 205 & 2,143 \\
\hline
\end{tabular}

${ }^{\mathrm{a}}$ Four solvents were used in this study: (1) MeOH, (2) DMSO, (3) hexane, and (4) PBS.

and MIT in MeOH and DMSO were fairly high (>0.99). In $\mathrm{MeOH}$, the RSD values of all target compounds exhibited the best reproducibility (below $6 \%$ for all target analytes), while in DMSO, the RSD values were slightly higher (mean RSD $(n=3)=8.09 \pm 2.13 \%)$. When PBS and hexane were used as solvents, the $R^{2}$ and RSD values of the target compounds differed upon changing the solvent types. In hexane, the $R^{2}$ values of benzene and toluene exhibited a strong linearity (>0.96), while that of MIT was low (0.0562). Also, benzene and toluene showed good RSD values in hexane $(<5 \%)$, whereas MIT had a high RSD (10.6\%). In contrast, the RSD and $R^{2}$ values when PBS was used as a solvent were contrary to those obtained in the case of hexane. In particular, the $R^{2}$ and RSD values of MIT in PBS were 0.9997 and $2.41 \%$, 
TABLE 3: Instrumental setup for the analysis of target compounds (B, T, and MIT).

(a) Carrier gas settings

Injection temperature

Injection mode

Carrier gas

Pressure

Column flow

Purge flow

Split ratio

TABLe 3. Instrumental setup for the analysis of target compounds (B, T, and $\mathrm{MIT}$ ).

(b) Gas chromatography (model: GC-2010, Shimadzu, Japan)

Column

250

Split

Helium (>99.999\%)

132.9

2.41

3.0

20

\author{
${ }^{\circ} \mathrm{C}$ \\ $\mathrm{kPa}$ \\ $\mathrm{mL} \cdot \mathrm{min}^{-1}$ (constant flow) \\ $\mathrm{mL} \cdot \mathrm{min}^{-1}$
}

Oven setting

(length: $60 \mathrm{~m}$, diameter: $0.25 \mathrm{~nm}$, and film thickness: $0.25 \mu \mathrm{m}$ ) $40^{\circ} \mathrm{C}(4 \mathrm{~min}) \longrightarrow 145^{\circ} \mathrm{C}\left(15^{\circ} \mathrm{C} / \mathrm{min}\right) \longrightarrow 285^{\circ} \mathrm{C}\left(70^{\circ} \mathrm{C} / \mathrm{min}\right)$

(Total program time $=13 \mathrm{~min}$ )

(c) Mass spectrometry (model: GCMS-QP2010 ultra, Shimadzu, Japan)

Ionization mode

EI $(70 \mathrm{eV})$

Ion source temperature $\quad 250$

Interface temperature $\quad 250$

TIC $30 \sim 500$

Scan speed 1000

$($ Total program time $=13$ min)

TABLE 4: Experimental results for three target compounds (benzene, toluene, and MIT) based on four different solvents (MeOH, hexane, $\mathrm{PBS}$, and DMSO), including the response factor $\left(\mathrm{RF}, \mathrm{ng}^{-1}\right)$, normalized-RF $\left(\mathrm{N}-\mathrm{RF}, \mathrm{ng}^{-1} / \mathrm{ng}^{-1}\right)$, determination of correlation $\left(R^{2}\right)$, relative standard deviation (RSD, \%), and limit of detection (LOD, ng).

\begin{tabular}{|c|c|c|c|c|}
\hline \multirow{2}{*}{ Solvent } & \multirow{2}{*}{ Factors } & \multicolumn{3}{|c|}{ Target compound } \\
\hline & & Benzene & Toluene & MIT \\
\hline \multirow{5}{*}{$\mathrm{MeOH}$} & $\mathrm{RF}\left(\mathrm{ng}^{-1}\right)$ & 26,164 & 43,618 & 7,877 \\
\hline & $\mathrm{N}-\mathrm{RF}^{\mathrm{a}}\left(\mathrm{ng}^{-1} / \mathrm{ng}^{-1}\right)$ & 0.79 & 0.55 & 0.87 \\
\hline & $R^{2}$ & 0.9978 & 0.9984 & 0.9994 \\
\hline & RSD (\%) & 0.83 & 0.72 & 5.56 \\
\hline & LOD (ng) & 0.02 & 0.01 & 0.07 \\
\hline \multirow{5}{*}{ Hexane } & $\mathrm{RF}\left(\mathrm{ng}^{-1}\right)$ & 33,674 & 78,604 & 1,117 \\
\hline & N-RF $\left(\mathrm{ng}^{-1} / \mathrm{ng}^{-1}\right)$ & 1 & 1 & 0.12 \\
\hline & $R^{2}$ & 0.9630 & 0.9969 & 0.0562 \\
\hline & RSD (\%) & 4.22 & 2.35 & 10.6 \\
\hline & LOD (ng) & 0.01 & 0.00 & 0.18 \\
\hline \multirow{5}{*}{ PBS } & $\mathrm{RF}\left(\mathrm{ng}^{-1}\right)$ & 11,286 & 21,026 & 9,067 \\
\hline & N-RF $\left(n g^{-1} / \mathrm{ng}^{-1}\right)$ & 0.34 & 0.27 & 1 \\
\hline & $R^{2}$ & 0.9788 & 0.9801 & 0.9997 \\
\hline & RSD (\%) & 16.2 & 14.6 & 2.41 \\
\hline & LOD (ng) & 0.01 & 0.01 & 0.01 \\
\hline \multirow{5}{*}{ DMSO } & $\mathrm{RF}\left(\mathrm{ng}^{-1}\right)$ & 31,932 & 60,147 & 8,148 \\
\hline & N-RF $\left(\mathrm{ng}^{-1} / \mathrm{ng}^{-1}\right)$ & 0.95 & 0.77 & 0.90 \\
\hline & $R^{2}$ & 0.9984 & 0.9995 & 0.9998 \\
\hline & RSD (\%) & 7.69 & 10.4 & 6.19 \\
\hline & LOD (ng) & 0.02 & 0.01 & 0.08 \\
\hline
\end{tabular}

${ }^{a}$ Normalized-RF (N-RF): RF value/maximum RF among four different solvents.

respectively, while the RSD values of benzene and toluene showed low reproducibility with above $14 \%$. The LOD values of all target analytes were below $0.18 \mathrm{ng}$, which is sufficient to detect the lowest calibration points of all the types of final working standards (F-WSs) (Table 4).

Based on these results, we concluded that the instrument responsivity and reproducibility of the target compounds differed, depending on their physicochemical properties. Moreover, the responsivity and analytical reliability was found to be especially affected by the solvent type. Therefore, in order to achieve an accurate quantitation, it is important to select the solvent by considering the physicochemical properties (i.e., polarity) of the target analytes.

3.2. Comparison of Previous Research Data. Diverse solvents have been previously used in chemical and biological analyses for the pretreatment of target samples and the preparation of standard solutions. In this study, we confirmed that the calibration results were different depending on the 


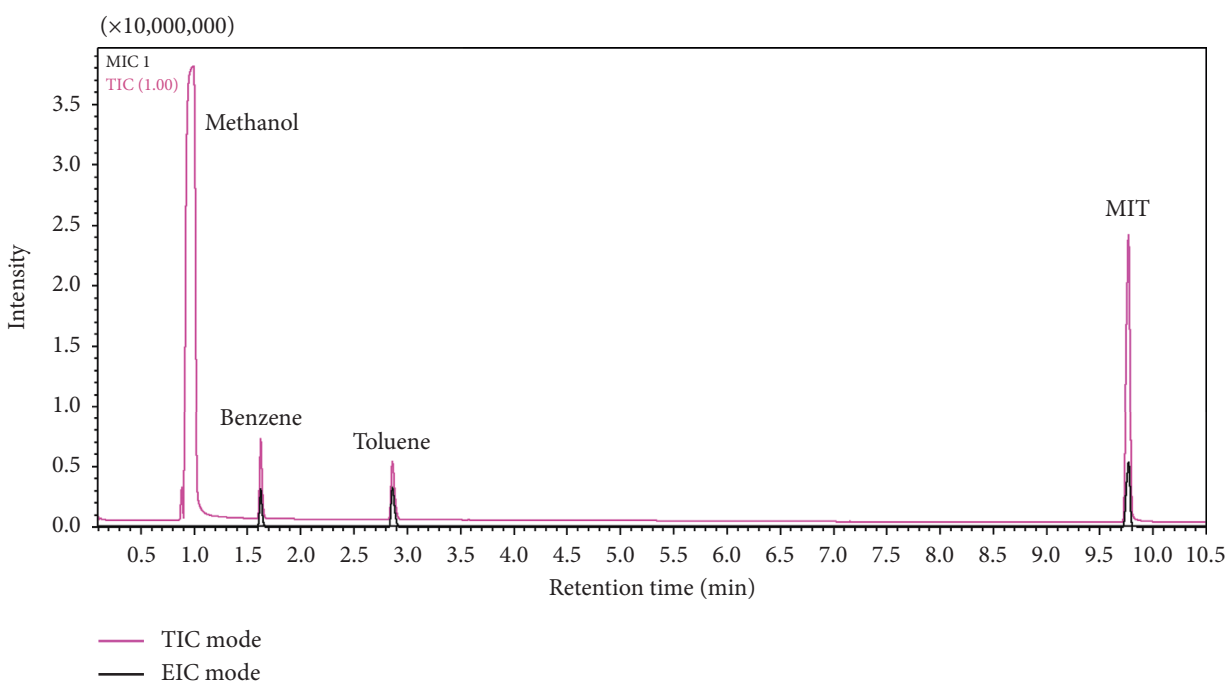

(a)

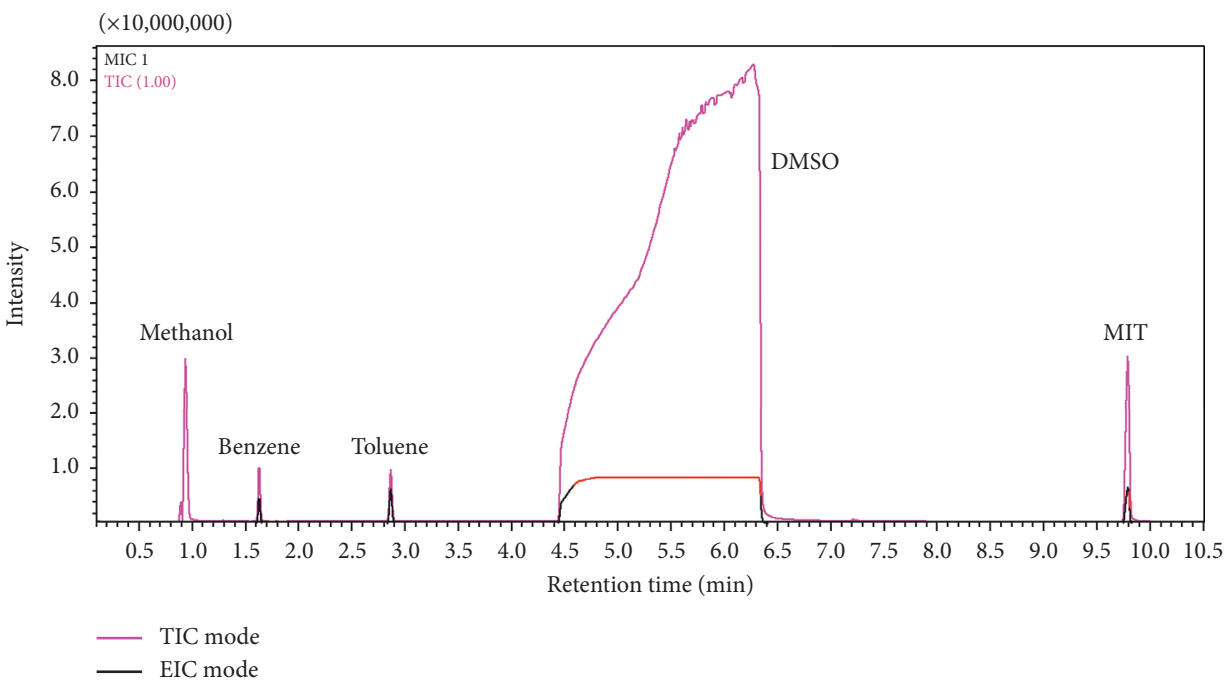

(b)

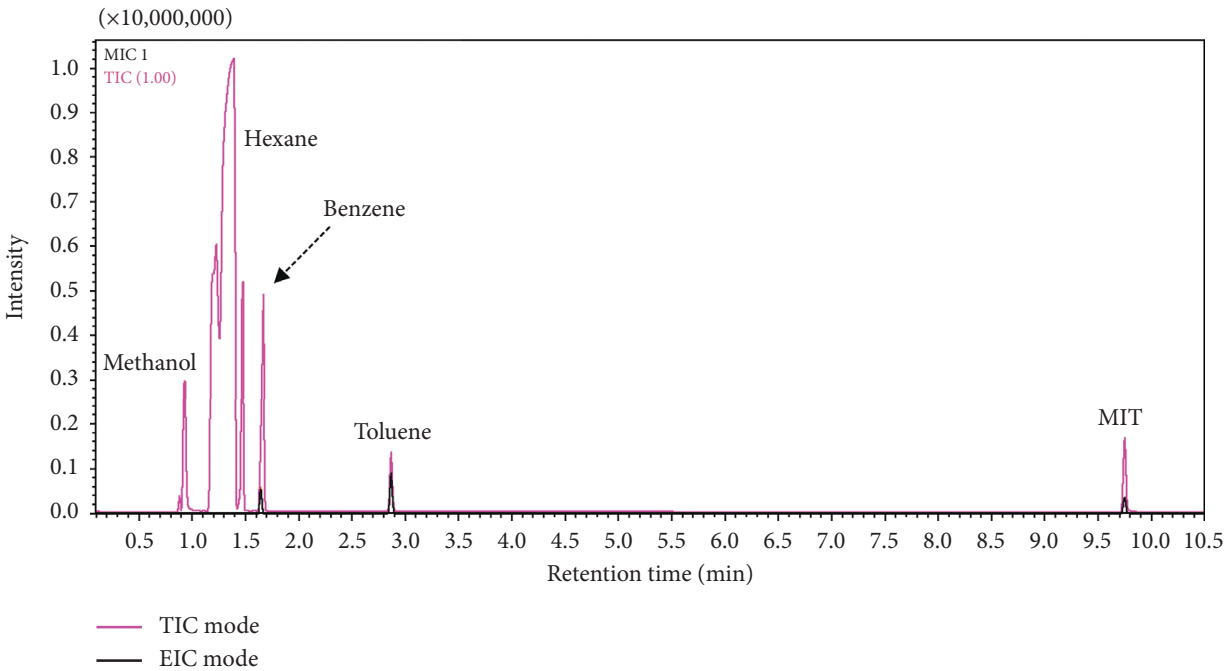

(c)

FIgUre 2: Continued. 


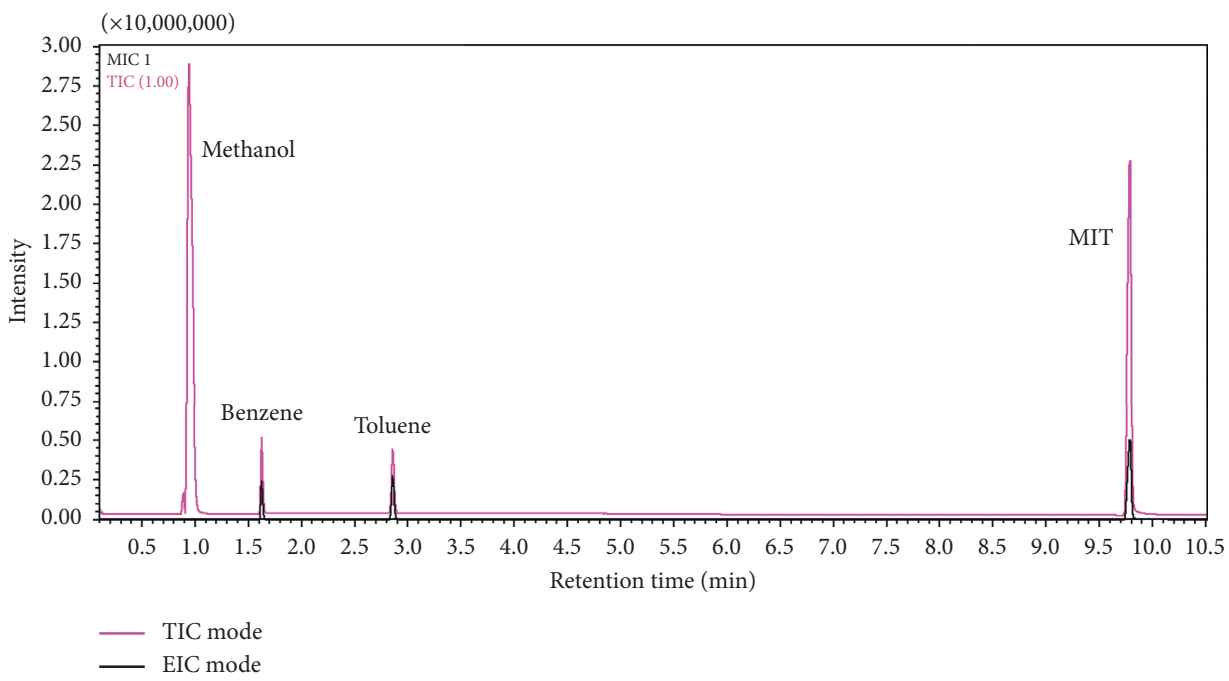

(d)

Figure 2: Chromatograms of the three target compounds based on four different solvents. The concentrations varied $208 \mathrm{ng} \mu \mathrm{L}^{-1}$ (benzene), $205 \mathrm{ng} \cdot \mu \mathrm{L}^{-1}$ (toluene), and 2,143 ng. $\mu \mathrm{L}^{-1}$ (MIT). (a) MeOH solvent. (b) DMSO solvent. (c) Hexane solvent. (d) PBS solvent.

TABle 5: List of the comparison of the solvent effects on chemical and biological analysis using the analytical instrument.

\begin{tabular}{|c|c|c|c|c|c|c|}
\hline Order & $\begin{array}{l}\text { Field of } \\
\text { science }\end{array}$ & $\begin{array}{l}\text { Target compound } \\
\text { or material }\end{array}$ & $\begin{array}{l}\text { Pretreatment or } \\
\text { standard solvent }\end{array}$ & Sample solvent & $\begin{array}{l}\text { Instrument or } \\
\text { assay method }^{\text {a }}\end{array}$ & Reference \\
\hline 1 & \multirow{3}{*}{ Chemistry } & $\begin{array}{c}13 \text { aldehydes and } 4 \\
\text { ketones }\end{array}$ & Water and acetonitrile & Water and methanol & HPLC-UV & Brandão et al. [23] \\
\hline 2 & & $\begin{array}{l}\text { Formaldehyde in bovine } \\
\text { milk }\end{array}$ & Ultrapure water & Acetonitrile & HPLC-UV & Rezende et al. [24] \\
\hline 3 & & $\begin{array}{l}\text { Sodium ferrocyanide in } \\
801 \text { Salt }\end{array}$ & $0.02 \mathrm{M} \mathrm{NaOH}$ & $0.02 \mathrm{M} \mathrm{NaOH}$ & HPLC-UV & Lim et al. [25] \\
\hline 4 & \multirow{5}{*}{ Biology } & Ginkgo biloba L. (EGB) & Methanol & $\begin{array}{l}\text { Isopropanol-ethanol- } \\
\text { water }(3: 2: 1)\end{array}$ & $\begin{array}{l}\text { HPLC-UV/DAD/ } \\
\text { MS }\end{array}$ & Yang et al. [26] \\
\hline 5 & & $\begin{array}{c}\text { Vitamin C (ascorbic acid } \\
\text { and dehydroascorbic } \\
\text { acid) }\end{array}$ & $\begin{array}{l}10 \% \text { meta-phosphoric } \\
\text { acid }\end{array}$ & $\begin{array}{l}10 \% \text { meta-phosphoric } \\
\text { acid }\end{array}$ & HPLC or UPLC & $\begin{array}{c}\text { Klimczak \& } \\
\text { Gliszczyńska- } \\
\text { Świgło [27] }\end{array}$ \\
\hline 6 & & $\begin{array}{l}\text { Sugars content in } \\
\text { sunflower oil }\end{array}$ & $0.005 \mathrm{~N} \mathrm{H}_{2} \mathrm{SO}_{4}$ & $\begin{array}{c}\text { Ethanol and distilled } \\
\text { water }\end{array}$ & HPLC & Baumler et al. [28] \\
\hline 7 & & \multirow[t]{2}{*}{37 raw vegetables } & $\begin{array}{l}\text { Acetone, methanol, } \\
\text { ethanol, and distilled } \\
\text { water }\end{array}$ & $\begin{array}{c}\text { 2,2-Diphenyl-1- } \\
\text { picrylhydrazyl (DPPH) } \\
\text { in ethanol }\end{array}$ & $\begin{array}{c}\text { DPPH free } \\
\text { radical } \\
\text { scavenging assay }\end{array}$ & \multirow[t]{2}{*}{$\begin{array}{c}\text { Sulaiman et al. } \\
\text { [29] }\end{array}$} \\
\hline & & & & Distilled water & $\begin{array}{l}\text { Total phenolic } \\
\text { content }\end{array}$ & \\
\hline
\end{tabular}

${ }^{a}$ HPLC, high-performance liquid chromatography; UV, ultraviolet/visible; DVD, diode array detection; UPLC, ultraperformance liquid chromatography.

solvent type, although the same target compounds were analyzed by the same analytical methods. However, many researchers do not fully consider the solvent effect in their quantitative analyses (Table 5).

For example, Rezende et al. [24] analyzed formaldehyde in bovine milk using high-performance liquid chromatography-ultraviolet/visible (HPLC-UV) by employing ultrapure water as a standard solvent and acetonitrile as a sample solvent. Moreover, Baümler et al. [28] analyzed sugars in sunflower oil samples using HPLC by extracting them with ethanol and subsequently diluting the samples with distilled water. Additionally, a $0.005 \mathrm{~N} \mathrm{H}_{2} \mathrm{SO}_{4}$ solution was used as a standard solvent. In both of these cases, there could be a quantitative error due to the solvent difference between the standards and samples.

Furthermore, there are also studies that use the same solvent for both standard and sample preparation. For instance, Lim et al. [25] analyzed ferrocyanide ions using HPLC-UV by employing the same solvent $(0.02 \mathrm{M} \mathrm{NaOH}$ solution) for the preparation of the standard solution and pretreatment of the sample. In addition, Klimczak and Gliszczyńska-Świgło [27] quantified vitamin C (ascorbic acid and dehydroascorbic acid) using HPLC and ultraperformance liquid chromatography (UPLC) systems by using $10 \%$ meta-phosphoric acid solvent to both extract the samples and dilute the standard solutions. In both of these 


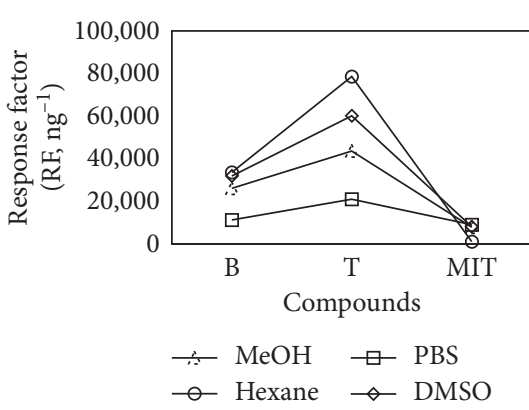

(a)

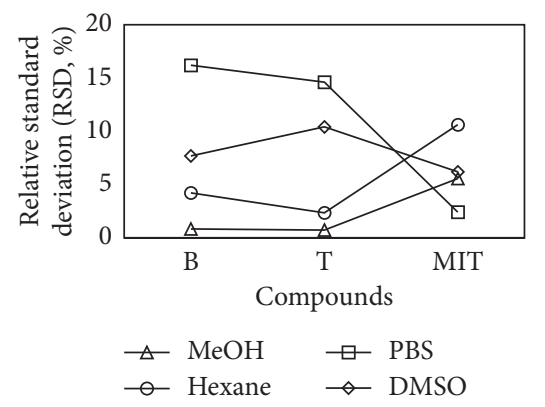

(d)

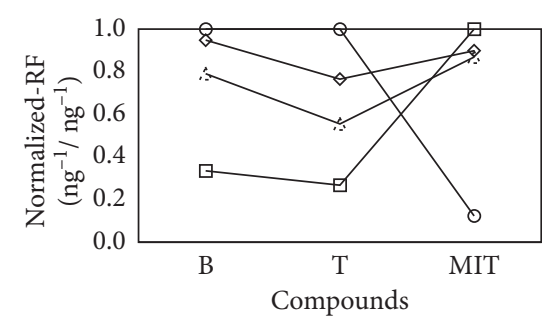

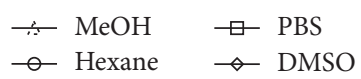

(b)
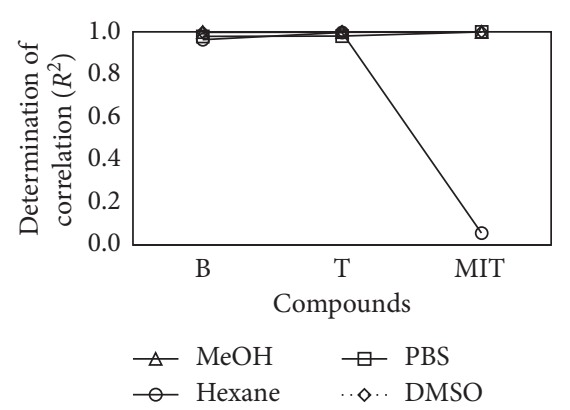

(c)

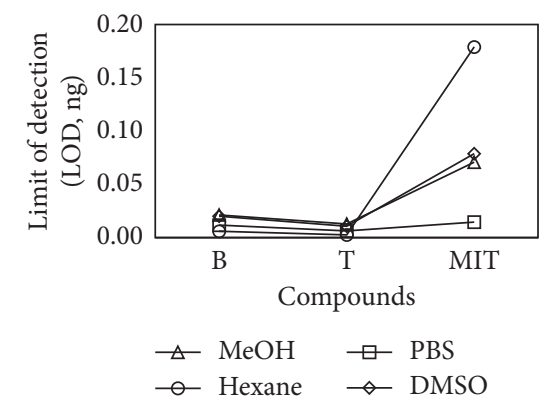

(e)

FIGURE 3: Plots of the calibration results from the three target compounds (B, T, and MIT) according to the four different solvents. (a) Response factor. (b) Normalized-RF. (c) Determination of correlation. (d) Relative standard deviation. (e) Limit of detection.

cases, the solvent effects could be minimized by using the same solvent for the quantitative analysis.

\section{Conclusion}

In order to conduct a toxicity testing, one needs to be able to obtain reliable quantitation data of the target toxic compounds. In this study, we assessed the effect of the solvent type on the quantitative results by analyzing three toxic compounds using four different solvents. Benzene, toluene, and MIT, which are well-known toxic compounds, were selected as target analytes. Liquid working standards of the target analytes were prepared using four different solvents $(\mathrm{MeOH}$, hexane, PBS, and DMSO), which are commonly used for extraction and dilution of sample solutions. These working standards were analyzed using GC-MS, thereby providing the calibration results of the target compounds according to the solvent type. The solvent effect was then assessed by comparing these results (Figure 3). The RF values of nonpolar compounds (benzene and toluene) were the highest $\left(33,674 \mathrm{ng}^{-1}\right.$ (benzene) and $78,604 \mathrm{ng}^{-1}$ (toluene)) in nonpolar solvents such as hexane and the lowest $\left(11,286 \mathrm{ng}^{-1}\right.$ (benzene) and $21,026 \mathrm{ng}^{-1}$ (toluene)) in the polar solvent such as PBS. Unlike benzene and toluene, MIT had the highest RF value $\left(9,067 \mathrm{ng}^{-1}\right)$ in a polar solvent (PBS), while it dropped dramatically to $1,117 \mathrm{ng}^{-1}$ in a nonpolar solvent (hexane). Additionally, in $\mathrm{MeOH}$, all target compounds showed fairly good reproducibilities with RSDs below $6 \%$ and linearity above 0.99 . In contrast, hexane induced a low $R^{2}$ value of MIT (0.0562), and PBS led to high RSD values of benzene and toluene (above 14\%).

All in all, the results of this study confirmed that the quantitative results were affected by the solvent effect. Since quantitative results can differ depending on the solvent type, it is important to select the solvent by considering the physicochemical properties (i.e., polarity) of the target compounds. In addition, the use of different solvents in the quantitative analysis, such as in the extraction and dilution processes, could lead to difficulties in obtaining reliable quantitative data.

\section{Data Availability}

The data used to support the findings of this study are included within the article.

\section{Conflicts of Interest}

The authors declare that they have no conflicts of interest.

\section{Acknowledgments}

This work was supported by the Korea Institute of Toxicology, Republic of Korea (KK-1803 and KK-1904).

\section{References}

[1] D. Lithner, A. Larsson, and G. Dave, "Environmental and health hazard ranking and assessment of plastic polymers based on chemical composition," Science of the Total Environment, vol. 409, no. 18, pp. 3309-3324, 2011.

[2] I. Silins and J. Högberg, "Combined toxic exposures and human health: biomarkers of exposure and effect," International Journal of Environmental Research and Public Health, vol. 8, no. 12, pp. 629-647, 2011. 
[3] R. Kroes, C. Galli, I. Munro et al., "Threshold of toxicological concern for chemical substances present in the diet: a practical tool for assessing the need for toxicity testing," Food and Chemical Toxicology, vol. 38, no. 2-3, pp. 255-312, 2000.

[4] G. E. Walsh, "Principles of toxicity testing with marine unicellular algae," Environmental Toxicology and Chemistry, vol. 7, no. 12, pp. 979-987, 1988.

[5] S. Zhang, S. Ali, Y. Kong et al., "Evolution of chemical structure of polydichlorophosphazene in various solvents and ways to prolong its stability," Journal of Molecular Liquids, vol. 225, pp. 536-543, 2017.

[6] B. Quinn, R. Gagne, and C. Blaise, "An investigation into the acute and chronic toxicity of eleven pharmaceuticals (and their solvent) found in wastewater effluent on the cnidarian, Hydra attenuata," Science of The Total Environment, vol. 389, no. 2-3, pp. 306-314, 2008.

[7] B.-S. Kim, Y.-K. Park, Y.-J. Yang et al., "Comparison of toxic response of cladocerans to organic solvents to establish the standard test guidelines using Korean native species," The Korean Journal of Pesticide Science, vol. 14, no. 1, pp. 10-15, 2010.

[8] J. L. Pereira, S. C. Antunes, B. B. Castro et al., "Toxicity evaluation of three pesticides on non-target aquatic and soil organisms: commercial formulation versus active ingredient," Ecotoxicology, vol. 18, no. 4, pp. 455-463, 2009.

[9] K.-H. Chang, J.-M. Park, C. H. Lee et al., "NADPH oxidase (NOX) 1 mediates cigarette smoke-induced superoxide generation in rat vascular smooth muscle cells," Toxicology in Vitro, vol. 38, pp. 49-58, 2017.

[10] S. J. Choi, S. H. Lee, S. J. Lee, M. J. Yang, and K. Lee, "Subchronic inhalation toxicity study of 3R4F reference cigarette smoke in rats," Molecular \& Cellular Toxicology, vol. 12, no. 3, pp. 313-325, 2016.

[11] G. L. Baker, A. Gupta, M. L. Clark et al., "Inhalation toxicity and lung toxicokinetics of C60 fullerene nanoparticles and microparticles," Toxicological Sciences, vol. 101, no. 1, pp. 122-131, 2008.

[12] Y.-S. Yang, J.-T. Kwon, I. Shim et al., "Evaluation of toxicity to triclosan in rats following 28 days of exposure to aerosol inhalation," Regulatory Toxicology and Pharmacology, vol. 71, no. 2, pp. 259-268, 2015.

[13] J.-H. Lee, H.-J. Kang, H.-S. Seol et al., "Refined exposure assessment for three active ingredients of humidifier disinfectants," Environmental Engineering Research, vol. 18, no. 4, pp. 253-257, 2013.

[14] K.-I. Lee, J.-H. Cho, and B.-S. Pyo, "Cytotoxicity and antioxidative activity of Artemisiae argi folium alcoholic extracts and their fractions," Korean Journal of Medicinal Crop Science, vol. 19, no. 6, pp. 421-425, 2011.

[15] B. Boonkaew, M. Kempf, R. Kimble, and L. Cuttle, "Cytotoxicity testing of silver-containing burn treatments using primary and immortal skin cells," Burns, vol. 40, no. 8, pp. 1562-1569, 2014.

[16] K. Reineke, R. Sevenich, C. Hertwig et al., "Comparative study on the high pressure inactivation behavior of the Shiga toxinproducing Escherichia coli O104:H4 and O157:H7 outbreak strains and a non-pathogenic surrogate," Food Microbiology, vol. 46, pp. 184-194, 2015.

[17] T. Hovav, S. Yedgar, N. Manny, and G. Barshtein, "Alteration of red cell aggregability and shape during blood storage," Transfusion, vol. 39, no. 3, pp. 277-281, 1999.

[18] H. Kim, Y. M. Cho, Y.-G. Seong, and H.-H. Seong, "Effects of acetamide and lactamide on the viability of frozen-thawed mammalian cells," Journal of Life Science, vol. 24, no. 11, pp. 1252-1257, 2014.

[19] M.-H. Lee and K.-H. Kim, "A study of calibration bias in the analysis of airborne carbonyl compounds between gaseous and liquid-phase standards by high performance liquid chromatography (HPLC)," Journal of Korean Society for Atmospheric Environment, vol. 28, no. 1, pp. 52-58, 2012.

[20] M. A. Ullah, K.-H. Kim, J. E. Szulejko, and D. W. Choi, "Quantitative approaches for the determination of volatile organic compounds (VOC) and its performance assessment in terms of solvent types and the related matrix effects," Asian Journal of Atmospheric Environment, vol. 11, no. 1, pp. 1-14, 2017.

[21] R. B. Campos, E. H. Santos, A. R. M. Oliveira et al., "Reactivity of imidazole derivatives toward phosphate triester in DMSO/ water mixtures: a comprehensive study on the solvent effect," The Journal of Organic Chemistry, vol. 80, no. 15, pp. 75727580, 2015.

[22] R. Bono, E. Scursatone, T. Schilirò, and G. Gilli, “Ambient air levels and occupational exposure to benzene, toluene, and xylenes in northwestern Italy," Journal of Toxicology and Environmental Health, Part A, vol. 66, no. 6, pp. 519-531, 2003.

[23] P. F. Brandão, R. M. Ramos, P. J. Almeida, and J. A. Rodrigues, "Determination of carbonyl compounds in cork agglomerates by GDME-HPLC-UV: identification of the extracted compounds by HPLC-MS/MS," Journal of Agricultural and Food Chemistry, vol. 65, no. 5, pp. 1037-1042, 2017.

[24] F. B. d. F. Rezende, A. M. d. S. S. Cheibub, A. D. P. Netto, and F. F. d. C. Marques, "Determination of formaldehyde in bovine milk using a high sensitivity HPLC-UV method," Microchemical Journal, vol. 134, pp. 383-389, 2017.

[25] H. S. Lim, J. Y. Hwang, E. Choi et al., "Development and validation of HPLC method for the determination of ferrocyanide ion in food grade salts," Food Chemistry, vol. 239, pp. 1167-1174, 2018.

[26] J. Yang, A.-Q. Wang, X.-j. Li, X. Fan, S.-S. Yin, and K. Lan, “A chemical profiling strategy for semi-quantitative analysis of flavonoids in Ginkgo extracts," Journal of Pharmaceutical and Biomedical Analysis, vol. 123, pp. 147-154, 2016.

[27] I. Klimczak and A. Gliszczyńska-Świgło, "Comparison of UPLC and HPLC methods for determination of vitamin C," Food Chemistry, vol. 175, pp. 100-105, 2015.

[28] E. R. Baümler, M. E. Carrín, and A. A. Carelli, "Extraction of sunflower oil using ethanol as solvent," Journal of Food Engineering, vol. 178, pp. 190-197, 2016.

[29] S. F. Sulaiman, A. A. B. Sajak, K. L. Ooi, Supriatno, and E. M. Seow, "Effect of solvents in extracting polyphenols and antioxidants of selected raw vegetables," Journal of Food Composition and Analysis, vol. 24, no. 4-5, pp. 506-515, 2011. 

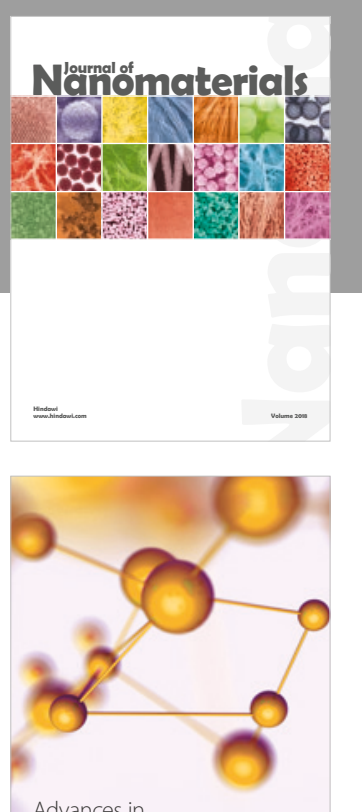

Physical Chemistry
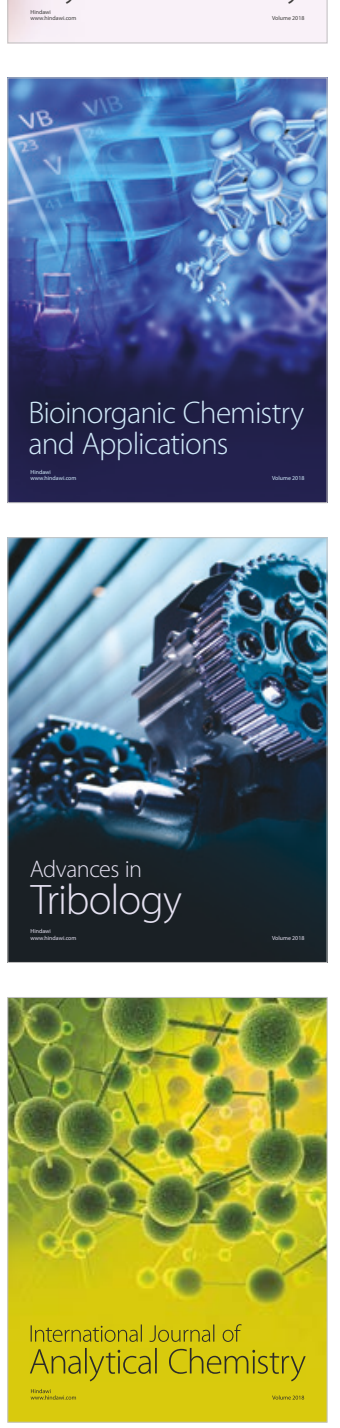

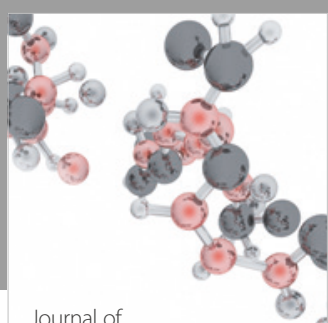

Analytical Methods

in Chemistry

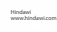

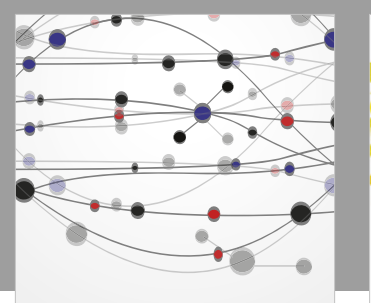

The Scientific World Journal

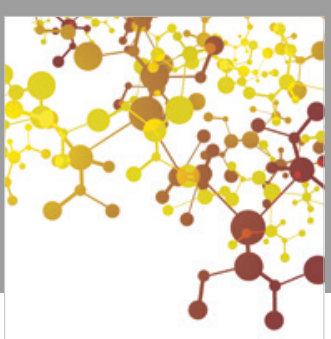

Journal of

Applied Chemistry
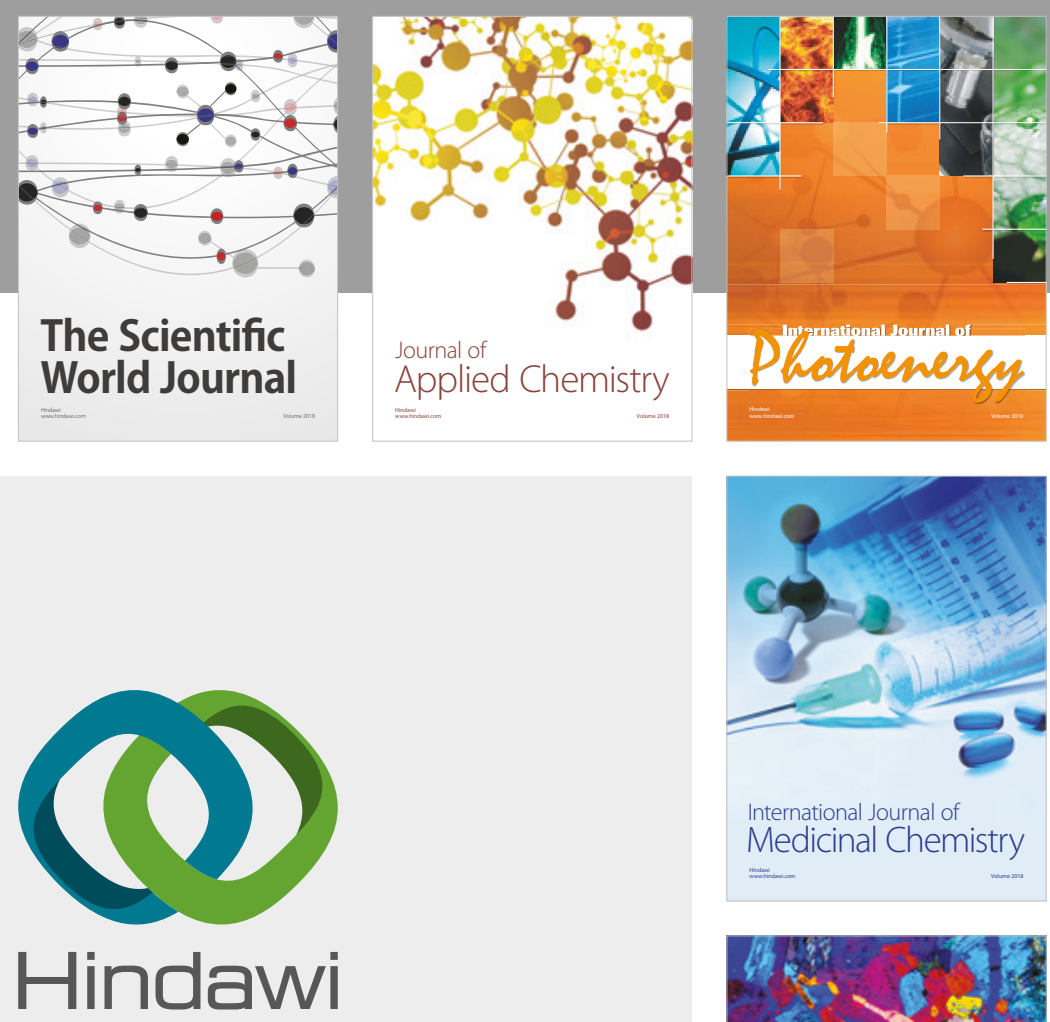

Submit your manuscripts at

www.hindawi.com
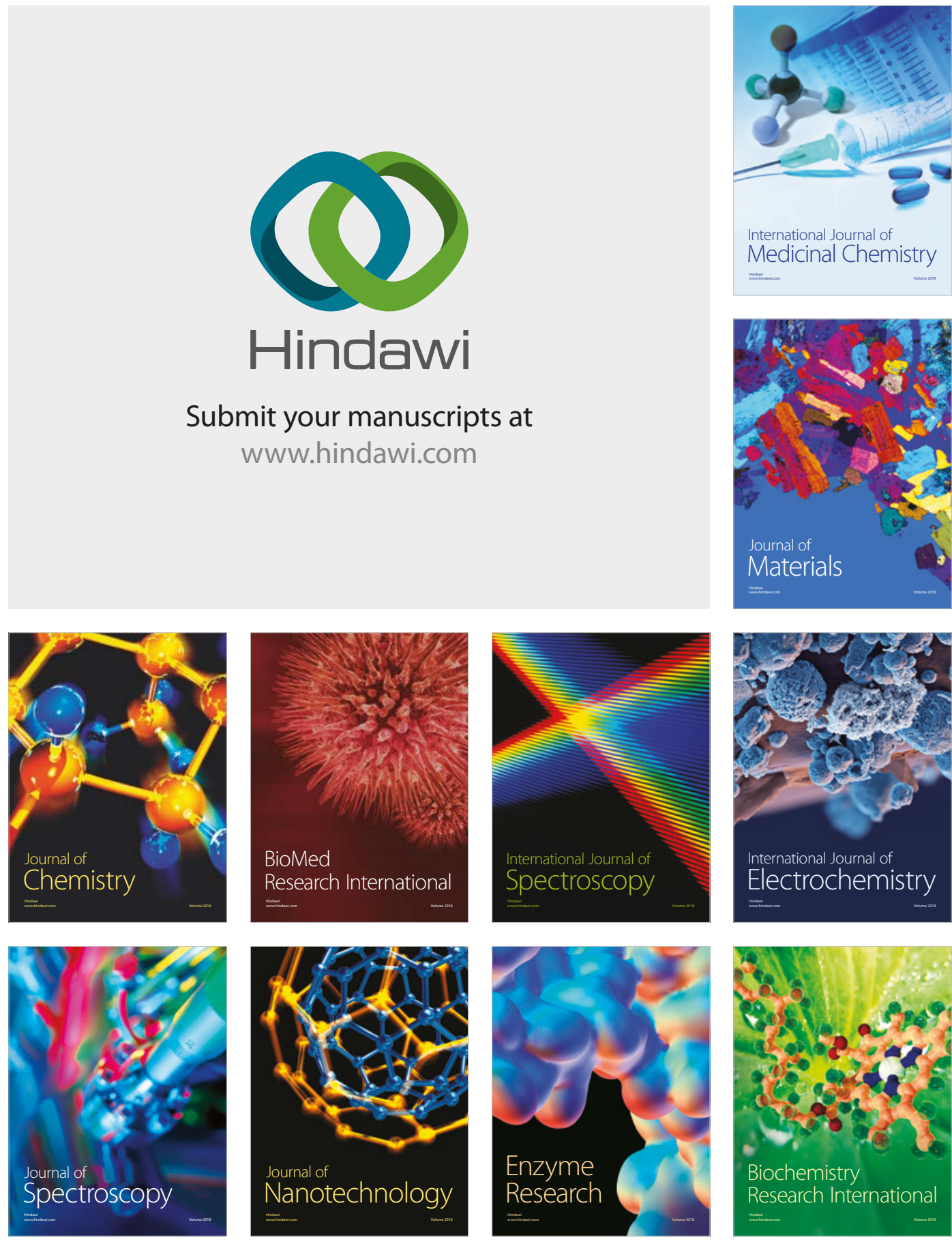
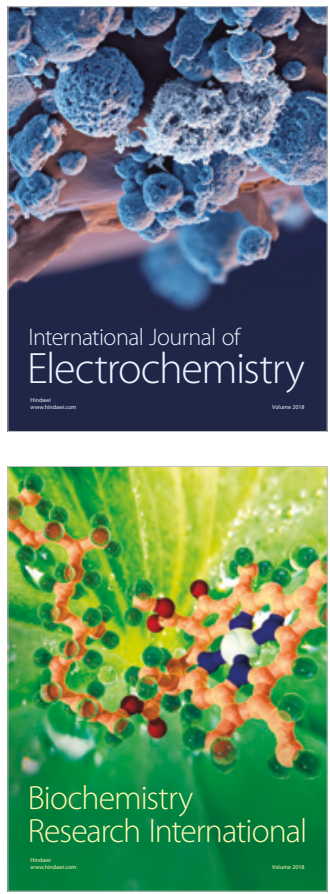